\title{
Math Matters: Comparison of the Math- ematics Requirements for Bachelor of Arts and Bachelor of Science Degrees in Canada
}

\author{
Ashley Nahornick \\ George Brown College
}

\begin{abstract}
Education matters. Every year, more students are pursuing postsecondary education. In fact, during the 2012-2013 academic year, over two million students were studying in Canadian postsecondary institutions, making it even more important to ensure that our students are getting the education and training they need to succeed. Notably, it is not uncommon for university students to struggle with mathematics or even to say, "I'm bad at math." Yet, at the heart of mathematics are critical thinking and careful questioning-skills needed in most jobs. In this paper, I feature a study exploring mathematics requirements at Canadian postsecondary institutions. Specifically, the study examines mathematics requirements for general Bachelor of Arts and Bachelor of Science degrees. The goal of the study is to offer potential suggestions to improve more students' mathematical abilities and better prepare them for future endeavours.
\end{abstract}

\section{Résumé}

Puisque l'éducation est très importante, un plus grand nombre d'étudiants poursuivent leurs études postsecondaires tous les ans. En effet, pendant l'année scolaire 2012-2013, plus de deux millions de jeunes étudiaient dans des établissements d'enseignement postsecondaires au Canada, ce qui met en relief l'importance de veiller à ce que ces étudiants obtiennent l'enseignement et la formation nécessaires à leur réussite. Néanmoins, il n'est pas rare que des 
étudiants universitaires éprouvent des difficultés en mathématiques ou qu'ils se qualifient de nuls en maths. Pourtant, la pensée critique et les interrogations minutieuses, deux compétences recherchées dans la plupart des emplois, se situent au cœur des mathématiques. Dans le présent article, j'expose une étude qui explore les exigences en mathématiques d'établissements postsecondaires du Canada. Plus précisément, l'étude examine les exigences en mathématiques pour l'obtention de tout baccalauréat ès arts (B.A.) et baccalauréat ès sciences (B.Sc.). L'objectif de l'étude est de proposer des moyens d'améliorer les aptitudes mathématiques de plus d'élèves afin de mieux les préparer pour l'avenir.

\section{Introduction}

Postsecondary education can change lives. According to Berger and Parkin (2009), postsecondary graduates are, in comparison with those who have only a high school diploma, likely to earn more money and more likely to be employed. During the 2012-2013 academic year, over two million students were studying in Canadian postsecondary institutions (Statistics Canada, 2014), underscoring the importance of ensuring that our students are getting the education and training they need to succeed and contribute to Canadian society.

In the same light, mathematics education matters. In fact, there is a large focus on improving mathematical skills in K-12 mathematics students through initiatives that emphasize problem posing, problem solving, and investigation. Yet, in many university classrooms, it is not uncommon to hear students say things like, "I am bad at math," or, "I'm a math-a-phobe." According to a survey conducted by Change the Equation, three out of 10 Americans said they consider themselves bad at math, and nearly a third of Americans reported they would rather clean a bathroom than do a math problem (Rick, 2010). But mathematics is everywhere, and most jobs require at least some proficiency in the subject. A background in math is needed to pursue technological development, to understand political and cultural issues, and simply in everyday life (Bishop, 1997), so it seems evident that mathematical proficiency matters. Students' struggles with mathematical abilities and confidence underscore the importance of conducting research on mathematics requirements and standards at Canadian postsecondary institutions.

The overall goals of this study were: (i) to gain insight into the mathematics requirements for the general Bachelor of Arts (BA) and Bachelor of Science (BSc) degrees offered at Canadian universities; and (ii) to offer suggestions for improving more students' mathematical abilities and better preparing them for future endeavours.

Through the use of university calendars, degree requirements, course listings, and academic overviews of BA and BSc degrees in Canada, data were collected and analyzed to better understand the minimum mathematics requirements. This study included all public Canadian universities with over 20,000 students enrolled $(n=23)$.

\section{Background on Higher Education in Canada}

In Canada, higher education is a provincial matter and therefore differs from province to province. There is no national accreditation board for universities; rather, each pro- 
gram of study is accredited by professional bodies, such as the Association of Accrediting Agencies of Canada (Marshall, 2004). Each of the 10 provinces and three territories establishes and maintains its own degree credentials, depending on its unique needs (Marshall, 2004). Since higher education differs in this way, there was a need for (i) research on the various mathematics requirements for BA and BSc degrees in Canada, as well as (ii) greater awareness of the diversity of requirements across these programs.

Universities in Canada are publicly funded (Marshall, 2008). The Association of Accrediting Agencies of Canada guarantees the quality and integrity of Canadian university programs and ensures that each university adheres to a common academic framework. It is important to note that this study is not questioning the Association of Accrediting Agencies of Canada but rather is seeking to raise awareness and find potential opportunities to improve mathematical abilities among our postsecondary students.

\section{Overview of Degrees}

There are over 10,000 undergraduate and graduate degree programs in Canada (Council of Ministers of Education, Canada, 2014), but the focus of this study is on two common undergraduate programs: the Bachelor of Arts (BA) and Bachelor of Science (BSc). At postsecondary institutions, students can receive diplomas, certificates, and university degrees. Diplomas usually take two years to complete, while certificates are shorter and more hands-on, and degrees require three or four years of full-time study. The BA and BSc degrees are normally four years and require a minimum of 120 credits (10 half-year courses a year) to complete (except in the province of Québec, where a degree generally takes three years of study and requires 90 credits). Students choose majors and minors on which they wish to focus their attention. They may also have to complete basic, broad course requirements set forth by the university. Students are admitted to the programs based on their high school credentials, except for in Québec, where students normally attend a pre-university system called CEGEP prior to entering university.

BA degrees focus on learning from a variety of humanities and social science disciplines, giving students opportunities to better understand political, economic, humanitarian, and social issues, both historical and contemporary. On the other hand, BSc degrees focus on scientific and technical learning opportunities. Nonetheless, the hope is that through either type of degree, students will forge opportunities for intellectual exploration and advancement.

\section{Problem Statement}

The purpose of this study was to determine the extent to which, for general BA and BSc degrees at Canadian universities, mathematics requirements differed.

The research questions were as follows:

1. What differences, if any, exist in the minimum mathematics requirements for general BA degrees at Canadian universities?

2. What differences, if any, exist in the minimum mathematics requirements for general BSc degrees at Canadian universities? 


\section{Method}

Through the use of university calendars, degree requirements, course listings, and academic overviews of BA and BSc degrees in Canada, I collected and analyzed data to better understand the minimum mathematics requirements. Please note that for this study, I considered only public Canadian universities with student populations of over 20,000, leaving 23 universities to be examined. Please note that the Université du Québec à Montréal, while maintaining a student population of over 20,000, was not considered in this study, because they do not offer four-year general arts or science degrees. In addition, McMaster University and Université Laval do not offer general science degrees and thus were not considered for the BSc part of the study. In addition, please note that I did not analyze the CEGEP system in Québec.

\section{Results}

The results show a range in mathematics requirements among general BA and BSc degrees. Interestingly, almost all BA programs examined had no required mathematics coursework, while for BSc programs the results were just about split, with $45 \%$ of universities requiring no mathematics and $55 \%$ requiring at least one mathematics class, if not more. It should be pointed out that the study examined the minimum required coursework for the general degree programs, but specific programs may have had additional mathematics requirements; students could also choose to take additional mathematics courses as electives. Table 1 summarizes general observations about mathematical study requirements for BA and BSc programs in Canada.

Table 1.

General Study Observations

\begin{tabular}{ll}
\hline Category & Observation \\
\hline $\begin{array}{l}\text { No mathematical } \\
\text { study required }\end{array}$ & $\begin{array}{l}\text { Almost all of the BA programs examined have no mathematics } \\
\text { requirements. } \\
\text { Slightly fewer than half of the BSc programs examined have no } \\
\text { mathematics requirements. }\end{array}$ \\
$\begin{array}{l}\text { Mathematical study } \\
\text { required }\end{array}$ & $\begin{array}{l}\text { More than half of the BSc programs examined require at least one } \\
\text { mathematics course, and some require up to three. }\end{array}$ \\
\hline
\end{tabular}

\section{Mathematics Requirements}

Mathematics requirements varied, but many universities had a similar approach to mathematics education. Table 2 provides a closer look at the specific requirements.

According to the data, most arts students do not have to take a mathematics course during their postsecondary education. In fact, almost all BA programs examined (in 21 out of 22 universities) have no mathematics requirements for general arts students. One school, the University of Manitoba, does require arts students to take one mathematics course and offers a number of options in this area. 
Table 2.

Mathematics Requirements for General Degrees

\begin{tabular}{lccl}
\hline Degree & \# of Universities & \% of Universities & Mathematics Requirements \\
\hline BA & $21 / 22$ & 95 & No mathematics required \\
& $1 / 22$ & 5 & At least one mathematics course required \\
BSc & $9 / 20$ & 45 & No mathematics required \\
& $3 / 20$ & 15 & 1 mathematics course required \\
& $6 / 20$ & 30 & 2 mathematics courses required \\
& $2 / 20$ & 10 & 3 mathematics courses required \\
\hline
\end{tabular}

It is important to point out that even though most of the BA programs have no mathematics requirements, some of have general education or quantitative education elements that require students to take a few courses with quantitative flair, such as business, economics, natural sciences, or mathematics; typically, however, mathematics courses are not prescribed, and in most cases are even avoided.

The BSc is a program cultivating scientific exploration, and yet there was a nearly even split among schools in terms of their mathematical requirements for BSc programs. A little less than 50\% (nine out of 20) of Canadian universities have no specific mathematics requirements, while $55 \%$ (11 out of 20) require at least one mathematics course. Although students may be obliged to take mathematics courses as prerequisites to other courses or as part of their major or minor, there is no specific mathematics requirement at many of the examined schools.

The institutions that require mathematics courses stipulate one, two, or three. Mount Royal University, the University of British Columbia, and the University of Guelph require one, which must be calculus. Six universities require students to take at least two courses in mathematics; four out of the seven schools mandate either two calculus courses or calculus and linear algebra courses, to meet the specified mathematics requirements. The other three universities-University of Manitoba, University of Waterloo, and McGill University-give students more freedom in selecting their mathematics courses, although the amount of flexibility depends on the institution. Some offer more distinctive courses as options, such as discrete mathematics, statistics, geometry, and combinatorics. Simon Fraser University and Concordia University require students to take three courses in mathematics. For both of these schools, two out of the three courses must be calculus. In the case of Simon Fraser University, the third course can be either statistics or probability, and for Concordia University, the third is linear algebra. Among all of the universities with mathematics requirements, calculus and linear algebra are cross-listed as permissible coursework and are often the required or suggested courses. Overall, there seem to be two camps: universities that do not require students to take mathematics coursework and those that require at least calculus.

\section{In-Depth Summary of Results}

The results from all of the universities examined are detailed below, in alphabetical order. 
Athabasca University. Athabasca University, located in Athabasca, Alberta, specializes in online and distance education. BA students have no specific mathematics requirements but must complete any two courses in the Faculty of Science. These can come from such diverse departments as astronomy, biology, environmental science, health studies, mathematics, or nutrition. BSc students must take two mathematics courses: one in linear algebra or calculus and one in statistics (Athabasca University, 2015).

Carleton University. Carleton University is located in Ottawa, Ontario, and sets no minimum mathematics requirements for the general BA or BSc programs. Specific majors or minors in these programs may require mathematics, but otherwise, students are not required to study mathematics beyond high school (Carleton University, 2015).

Concordia University. Concordia University, located in Montréal, Québec, has no required mathematics courses for BA students but requires BSc students to complete three mathematics courses in calculus and linear algebra (Concordia University, 2015).

McGill University. McGill University, also located in Montréal, is a bilingual university where the primary language of instruction is English. For the BA, students are not required to take any mathematics credits but must take a minimum of two courses in the Faculty of Science. Students may choose to forgo mathematics courses for other, more avant-garde courses offered in the Faculty of Science, such as the science of storms, or atmospheric and ocean dynamics. This means that, unfortunately, mathematics courses are not always promoted. However, the BSc requirements are much more stringent. McGill requires BSc students to choose either two courses in mathematics or four courses in biology, chemistry, or physics; or to take three courses in mathematics and three courses in biology, chemistry, or physics. Students can choose from four mathematics courses to meet the criteria: linear algebra and geometry, enriched linear algebra and geometry, calculus I, and calculus II. This does not give students much flexibility or introduction into other areas of mathematics; rather, the focus is on traditional applied mathematics (McGill University, 2015).

McMaster University. McMaster University, located in Hamilton, Ontario, does not require BA students to complete any mathematics courses. As mentioned previously, McMaster does not offer a general BSc degree and thus was not considered in the second part of the study (McMaster University, 2014).

Mount Royal University. Mount Royal University is located in Calgary, Alberta. The BA program does not require students to complete mathematics courses; however, they must complete 12 courses in general education, which can include mathematics. General education courses encompass a wide variety of subject areas, including forensic science, poetry, writing, communication, health science, and general sciences. With so many available options, mathematics courses may fall to the wayside when students are selecting their coursework (Mount Royal University, 2014).

Queen's University. Queen's University of Kingston, commonly known as Queen's University, is located in Kingston, Ontario. Students enrolled in the general BA and BSc programs are not required to take any mathematics coursework, although specific concentrations may stipulate mathematics courses (Queen's University, 2014).

Ryerson University. Located in downtown Toronto, Ontario, Ryerson University has more than 36,000 undergraduate students. At Ryerson, the BA program has no specified mathematics requirements, but the BSc program requires all students to complete two calculus courses. Students can also choose to take additional mathematics coursework beyond calculus (Ryerson University, 2014). 
Simon Fraser University. Simon Fraser University is located in Burnaby, British Columbia, with other campuses in downtown Vancouver and Surrey. No mathematics courses are required for the BA program. However, arts students must complete two courses from the physical sciences, such as chemistry, earth sciences, mathematics, or physics. The BSc program, on the other hand, requires three courses in mathematics-two calculus classes and a course in statistics or probability (Simon Fraser University, 2014).

Université de Montréal. The Université de Montréal, located in Montréal, Québec, has no mathematics requirements for the BA or BSc programs (Université de Montréal, 2014).

Université Laval. Université Laval is a French university located in Québec City. The BA program has no specified mathematics requirements. As mentioned earlier, Université Laval does not offer a four-year general BSc program and therefore was not considered for the BSc analysis (Université Laval, 2014).

University of Alberta. The University of Alberta is located in Edmonton, Alberta. While the BA has no specific mathematics requirements, students must complete a minimum of two courses of their choosing within the Faculty of Science. Thus, an arts student from the University of Alberta may have no formal mathematics training beyond high school. Although students completing BSc degrees also have no specific mathematics requirements, each must complete a minimum of two courses in the Departments of Computing Science and/or the Department of Mathematics. Approved mathematics courses include calculus I, calculus II, linear algebra, elementary theory of interest, and introduction to statistics. Prerequisites for other courses may dictate the specific classes to meet the computer science and mathematics requirement (University of Alberta, 2014).

University of British Columbia. The University of British Columbia, located in Vancouver, British Columbia, boasts a student population of over 54,000. There are no mathematics requirements for students in the BA program. However, as a part of a broad and basic criterion, students are required to take a minimum of two courses from the Faculty of Science. Such courses can indeed be mathematics or statistics, but then again, with the vast array of interesting courses in the Faculty of Science (such as psychology, forestry, and geology), courses in mathematics may be overlooked. On the other hand, students pursuing a BSc must complete three courses in computational sciences. One course must be calculus, with some choice on the focus of the calculus course, such as health sciences or business. The other two can be in computer science, mathematics, or statistics (University of British Columbia, 2014).

University of Calgary. The University of Calgary, located in Calgary, Alberta, does not stipulate mathematics requirements for their general BA and BSc programs (University of Calgary, 2014).

University of Guelph. The University of Guelph is located in Guelph, Ontario. Students in the BA program are not required to take mathematics courses but must complete two classes in natural or mathematical sciences as part of their program. For BSc students, one calculus course is required, and students cannot replace this calculus course with other computational alternatives (University of Guelph, 2014).

University of Manitoba. The University of Manitoba, is located in Winnipeg, Manitoba. To be granted BA degrees, students must complete a minimum of one course in mathematics, as well as two additional courses in the Faculty of Science, which includes 
the Department of Mathematics. Students can complete any mathematics course of their choosing. Examples of first-year mathematics offerings include applied finite mathematics, calculus, discrete mathematics, linear algebra, and mathematics in art. The requirements are slightly more stringent for BSc students, who must complete a minimum of two mathematics courses. They can take classes such as calculus, discrete mathematics, geometry and linear algebra, and statistics (University of Manitoba, 2014).

University of Ottawa. The University of Ottawa is located in Ottawa, Ontario. Neither the general BA nor the BSc program has a mathematics requirement, although certain programs of study within those degrees may require mathematics courses (University of Ottawa, 2014).

University of Toronto. The University of Toronto, located in Toronto, Ontario, does not require students in either the BA or the BSc programs to take any mathematics credits. However, both BA and BSc students must take two courses in the Faculty of Science, with the option to take two more courses in the physical and mathematical sciences. Specific mathematics course requirements depend on each student's major or minor (University of Toronto, 2014).

University of Victoria. The University of Victoria, located in Victoria, British Columbia, does not have minimum mathematics requirements for BA and BSc general programs. Specific majors or minors may have mathematic requirements (University of Victoria, 2014).

University of Waterloo. The University of Waterloo is located in Waterloo, Ontario. BA students are not required to complete mathematics courses as part of their degrees, but BSc students must complete two courses in mathematics. Students are allowed to take a variety of mathematics courses to complete this requirement, including actuarial science, applied or pure mathematics, combinatorics and optimization, computer science, or statistics (University of Waterloo, 2014).

University of Western Ontario. University of Western Ontario, commonly known as Western University, is located in London, Ontario. Western does not require BA or BSc students to complete mathematics coursework as part of their academic program, but students are free to take mathematics courses if they wish. Certain majors or minors may require mathematics courses (University of Western Ontario, 2013).

York University. York University, located in Toronto, Ontario, has over 45,000 students. The BA program does not require students to complete any specific mathematics coursework, and while students are required to take two courses in natural sciences, mathematics courses cannot be counted towards this requirement. This limits students' possible exposure to mathematics. By contrast, the mathematics requirements for the BSc are much more rigid, as students must take a minimum of two mathematics courses in either calculus or linear algebra (York University, 2014).

\section{Discussion}

The goal of this study was to explore whether mathematics requirements across Canadian institutions for BA and BSc degrees are consistent. Degree uniformity is important for students, universities, and employers alike. Fundamentally, (i) students attend university to get the training and education they need to succeed, (ii) universities want to provide consistent educational programs, and (iii) employers want to know that they are 
hiring graduates who have the necessary skills for the modern economy. Mathematical proficiency is normally a trait important to employers; it is not uncommon for a candidate in a job interview to be asked to solve a business case study, for example, or to complete a job test to demonstrate relevant skills that include mathematics. If a student believes that he or she is "bad at math," then these types of situations may be challenging and stressful.

It should be our goal to produce the best graduates possible, which includes ensuring that our graduates have strong mathematical proficiency. Thus, it is important for there to be greater awareness of the differences in mathematics requirements across programs. The results of the study demonstrate that general degree requirements for mathematics coursework in BA and BSc programs vary significantly across the nation. The extent to which the mathematics requirements differ, however, depends on the institution and province studied.

The data show that with the exception of the University of Manitoba, BA programs require no mathematics study; at that institution, students have quite a bit of choice in terms of the type of mathematics course they opt to take. I did not expect to find that so many schools do not require arts students to take a course in mathematics. In most arts degrees, students are required to take a few courses in the Faculty of Science, and they may elect to take a mathematics course, but with so many other options (such as biology, earth science, nutrition, and psychology), mathematics is probably not most students' first choice. Yet, although mathematics is not an arts-related discipline, it is important for all students to be comfortable with mathematics. Taking a mathematics course in reasoning, problem solving, or the like might boost students' mathematical abilities and confidence.

There is a wide range of mathematical requirements for BSc programs. Just less than $50 \%$ (nine out of 20) of the universities examined have no specific mathematics requirements for their BSc programs, although students may be obliged to take mathematics courses as prerequisites to other courses or as part of their major or minor. Fifty-five percent (11 out of 20) of the universities require BSc students to complete at least one mathematics course. For the majority of these schools, calculus is mandatory. While calculus is a useful subject, there are many other types of mathematics-such as problem solving, mathematical modeling, statistics, business math, and mathematical reasoning - that may be more suitable for students' career goals. Some universities do allow students a measure of choice in selecting their mathematics courses, but the amount of flexibility depends on the institution and the program of study. Calculus and linear algebra are crosslisted among all universities, although some institutions offer more distinctive courses, such as biostatistics, discrete structure, mathematical modeling, mathematical reasoning, statistics, and theory of interest. Overall, the results show a good deal of diversity among mathematics requirements for the BSc program across Canada.

\section{Limitations and Considerations}

One of this study's limitations was that only universities with over 20,000 students were considered. Future studies could look at all 95 Canadian institutions. In addition, future studies could add further sources of information, such as interviews with administrators and professors, to gain a greater understanding of current disparities.

An additional consideration here is that even with specific mathematics requirements, students may elect to take more mathematics courses than prescribed. This leads to the 
question of whether the majority of students do indeed enrol in more mathematics courses than the minimum required. Additional studies with in-depth student statistics would be required to answer this question.

Another supplement to this study that could shed more light on current mathematics standards in Canada would be to look at historical degree requirements, from universities' inception up to the present. How have the requirements changed? Have they become more stringent? In addition to this, an in-depth analysis of the CEGEP system in Québec could give researchers additional understanding of mathematical requirements at Québec universities.

Finally, these results raise the question of whether Canadian institutions should create cohesive and uniform mathematics standards. Would students be better served with such a system? It would also be beneficial to compare Canada to other countries, particularly Organisation for Economic Co-operation and Development (OECD) countries; for example, do other OECD countries maintain uniform mathematics standards for undergraduate degrees? To add to the discussion: even if strenuous mathematics requirements were set forth, would these courses achieve the purpose of the degree? Would students' mathematical abilities improve? These are the types of questions that remain to be answered, and all of these questions would help foster discussion and better mathematics education in Canada.

\section{Conclusion}

All in all, there are many further discussions that could be had regarding mathematics requirements among Canadian universities. The BA and BSc degree programs have different intentions, and it is clear that the mathematics requirements for these programs differ among universities. There is, however, some similarity. For example, 22 of the 23 universities studied have no mathematics requirements for the BA program, while nine of the 20 that offer BSc degrees also have no mathematics requirement for that program. Eleven of the universities require students to complete at least one mathematics course, although the exact courses permitted vary. At all of the universities, calculus courses meet the requirement, and in most cases, the mandatory mathematics courses focus on calculus or linear algebra but do not give students avenues to explore other types of mathematics, such as business, mathematical reasoning, problem solving, or statistics. Thus, we must continue to ask ourselves about potential ways-such as looking at program requirements-to improve students' mathematical abilities and better prepare them for the future.

\section{References}

Athabasca University. (2015). Undergraduate calendar. Retrieved from http:// calendar.athabascau.ca/undergrad/current/

Berger, J., Motte, A., \& Parkin, A. (2009). The price of knowledge: Access and student finance in Canada (4th ed.). Montréal, QC: The Canadian Millennium Scholarship Foundation.

Bishop, A. J. (1997). International handbook of mathematics education. New York, NY: Springer. 
Carleton University. (2015). 2014-2015 undergraduate calendar. Retrieved from http://calendar.carleton.ca/undergrad/undergraduniversity/academicyear/

Concordia University. (2015). Undergraduate calendar 2014-2015. Retrieved from http://www.concordia.ca/academics/undergraduate/calendar/2014-15.html

Council of Ministers of Education, Canada. (2014, October 24). Study in Canada. Retrieved from http://www.educationau-incanada.ca/educationau-incanada/studyetudes/index.aspx?lang=eng

Employment and Social Development Canada. (2015, June 18). Indicators of wellbeing in Canada. Retrieved from http://well-being.esdc.gc.ca/misme-iowb/h.4m.2@eng.jsp

Linehan, P. L. (1998). Conceptions of ability: Nature and impact across content areas. Retrieved from ProQuest Digital Dissertations. (AAI 9921102)

Marshall, D. (2004). Degree accreditation in Canada. Canadian Journal of Higher Education, 34(2), 69-96. Retrieved from http://ojs.library.ubc.ca/index.php/cjhe/ article/view/183457

Marshall, D. (2008). Differentiation by degrees: System design and the changing undergraduate environment in Canada. Canadian Journal of Higher Education, 38(3), 1-20. Retrieved from http://ojs.library.ubc.ca/index.php/cjhe/article/view/499

McGill University. (2015). Program calendars. Retrieved from http://www.megill. ca/students/courses/calendars

McMaster University. (2014). Undergraduate calendar. Retrieved from http:// academiccalendars.romcmaster.ca/index.php?catoid $=7$

Mount Royal University. (2014). Academic calendar. Retrieved from http://www. mtroyal.ca/academicsupport/AcademicCalendar/index.htm

Queen's University. (2014). Faculty of Arts and Science academic calendar. Retrieved from http://www.queensu.ca/learn/academiccalendars

Rick. (2010, September 16). In a New Survey, Americans say, "We're Not Good At Math" [Text]. Retrieved January 2, 2015, from http://changetheequation.org/press/newsurvey-americans-say-\%E2\%80\%9Cwe\%E2\%80\%99re-not-good-math\%E2\%80\%9D

Ryerson University. (2014). Ryerson University undergraduate calendar 2014-2015. Retrieved from http://www.ryerson.ca/calendar/2014-2015/

Simon Fraser University. (2014). Academic calendar. Fall 2014. Retrieved from http://www.sfu.ca/students/calendar/2014/fall.html

Statistics Canada. (2014, November 25). Postsecondary enrolments by institution type, registration status, province and sex (both sexes). Retrieved from http://www. statcan.gc.ca/tables-tableaux/sum-som/lo1/cst01/educ71a-eng.htm

Université de Montréal. (2014). Calendrier universitaire 2013-2014. Retrieved from http://www.etudes.umontreal.ca/calendrier/cal_universitaire_13-14.html

Université Laval. (2014). Calendrier universitaire 2014-2015. Retrieved from http:// www2.ulaval.ca/les-etudes/programmes-cours-horaire/calendriers-universitaires.html 
University of Alberta. (2014). Calendar 2014-2015. Retrieved from http://www. registrar.ualberta.ca/calendar-archive/calendar-2014-2015/index.html

University of British Columbia. (2014). Vancouver academic calendar 2014/2015. Retrieved from http://www.calendar.ubc.ca/archive/vancouver/1415/

University of Calgary. (2014). University of Calgary calendar 2014-2015. Retrieved from http://www.ucalgary.ca/pubs/calendar/archives/2014/index.htm

University of Guelph. (2014). 2014-2015 undergraduate calendar. Retrieved from https://www.uoguelph.ca/registrar/calendars/undergraduate/2014-2015/

University of Manitoba. (2014). Academic calendar 2014-2015. Retrieved from http:// umanitoba.ca/student/records/media/UG_AC_2014-2015_Updated_Feb10_2015.pdf

University of Ottawa. (2014). Undergraduate programs and courses. 2014-2015 calendars. http://www.uottawa.ca/academic/info/regist/1415/calendars/

University of Toronto. (2014). Faculty of Arts and Science. 2014-2015 calendar. Degree requirements (H.B.A., H.B.Sc., BCom). Retrieved from http://www. artsandscience.utoronto.ca/ofr/archived/1415calendar/index.html

University of Victoria. (2014). The University of Victoria Calendar 2014-2015. Retrieved from http://web.uvic.ca/calendar2014-09/

University of Waterloo. (2014). Undergraduate studies academic calendar. Retrieved from http://ugradcalendar.uwaterloo.ca/page/uWaterloo-Undergraduate-Calendar-Access

University of Western Ontario. (2013). The University of Western Ontario academic calendar 2013. Retrieved from http://www.westerncalendar.uwo.ca/Archive/2013/2013/

York University. (2013). The B.A. degree: The basics. Retrieved from http://calendars. registrar.yorku.ca/2014-2015/faculty_programs/AP/humanities.htm

York University. (2014). Academic calendars. Retrieved from http://calendars. registrar.yorku.ca/

\section{Contact Information}

Ashley Nahornick

George Brown College

ashley.nahornick@georgebrown.ca

Ashley Nahornick is a mathematics educator at George Brown College, in Toronto. Her passion is educational policy and instructional practice in mathematics education. 